\title{
PROVISION CAPACITY OF SERVICE DELIVERY FACILITIES FOR CHILDREN WITH HEARING LOSS IN HAI PHONG, VIETNAM
}

\author{
XUONG TUYET NGUYEN ${ }^{1 *}$, HA NGOC NGUYEN ${ }^{2}$, TRAM VAN TA ${ }^{3}$, VU KIEN TRAN ${ }^{4}$, HIEN THE PHAM \\ ${ }^{1}$ Department of Ear-Nose-Throat, Vietnam National Hospital of Paediatrics, Hanoi 100000, Vietnam. ${ }^{2}$ Department of Ear-Nose-Throat, \\ Viet Tiep Friendship Hospital, Haiphong 180000, Vietnam. ${ }^{3}$ Department of Paediatrics, Tien Giang General Hospital, Tien Giang Province \\ 860000, Vietnam. ${ }^{4}$ Department of Surgery, Tra Vinh General Hospital, Tien Giang Province 860000, Vietnam. ${ }^{5}$ Department of Medicine \\ and Pharmacy, Tra Vinh University, Tra Vinh Province 940000, Vietnam. Email: nguyenxuongnhp@yahoo.com
}

Received: 27 August 2019, Revised and Accepted: 10 September 2019

\section{ABSTRACT}

Objective: Hearing loss is a commonly occurring disability that affects 466 million people worldwide. This study aimed at determining the actual situations of early intervention delivery facilities for children with hearing loss. Out of this affected population, $7 \%$ are children (34 million) who, along with their families, grapple with the serious lifelong problems that accompany the disease.

Methods: This descriptive cross-sectional study was conducted with facilities investigated consisting of a school for the deaf, hospitals, an audiology center, and a social agency in Hai Phong province from January 2013 to December 2014 . A sample composed of 353 children was also recruited.

Results: The examined facilities suffer from shortcomings in provision capacity, which manifest in deficient materials, supplies and equipment, and human resources; the lack of interdisciplinary coordination of activities; inadequate community awareness; and the unaddressed need for early detection and intervention. The conditions of most of the children (98\%) were detected by their families, and among those who were clinically diagnosed, the majority (76.8\%) received such diagnosis at central hospitals. Hearing impairment among the children were detected, diagnosed, and subjected to intervention at a very late stage (on average, at ages $22.3,34$, and 32.5 months, respectively), thereby compelling up to $63.6 \%$ of the families to struggle with their children's hearing loss.

Conclusion: Solutions to current interventions are needed to enhance service delivery systems and guarantee early detection as well as timely and appropriate treatment.

Keywords: Hearing loss, Deaf children, Early intervention, Service delivery system, Vietnam.

(c) 2019 The Authors. Published by Innovare Academic Sciences Pvt Ltd. This is an open access article under the CC BY license (http://creativecommons. org/licenses/by/4. 0/) DOI: http://dx.doi.org/10.22159/ajpcr.2019.v12i10.35483

\section{INTRODUCTION}

Hearing loss is an increasingly prevalent disability [1] whose effects are felt all over the world by 466 million people, of whom $7 \%$ are children (34 million) who, together with their families, are forced to endure serious problems throughout life [2]. Correspondingly, the early detection of hearing impairment and its timely and appropriate treatment plays an important role in helping children develop speech and language abilities and experience a sense of social inclusion [3]. Providing adequate early intervention services also helps families strengthen their interactions with their children [4].

Many developed countries that have applied early intervention measures for deaf children have become the standard of child health-care and national target programs [5]. In Japan, for instance, children who receive intervention under 6 months of age respond better to treatment than do those who receive medical attention at 6 months [6]. An important issue for consideration, however, is that intervention models vary in terms of scale, content, implementation, and service quality because of differences in socioeconomic conditions and circumstances between developed and developing countries [5]. A case in point is Vietnam, where early intervention for hearing-impaired children is still in its infancy and is, therefore, confronted with many challenges [7]. Some of these difficulties include an as yet unestablished intervention system and the lack of services that sufficiently meet demand from deaf children and their families [7]. In addition, few specific programs have been created to support the development of early intervention services at the grassroots level, even though authorities have policies in place to guide and encourage such endeavors. In Vietnamese localities, such as Hai Phong, identifying inadequacies in the provision of early intervention services is an urgent need. Addressing this problem can advance the use of scientific and practical evidence as grounding in the formulation of solutions that strengthen the effectiveness of current systems in offering early detection and treatment for hearing-impaired children. Motivated by these issues, this study investigated the supply capacity of facilities providing early intervention services to deaf children in Hai Phong, Vietnam.

\section{METHODS}

Study design and study sites

This descriptive cross-sectional study was conducted from January 2013 to December 2014 at six early intervention facilities for children with hearing loss. These establishments were the Hai Phong Deaf School, Viet Tiep Hospital, Children's Hospital, Hai Phong Hospital of Obstetrics and Gynecology (OG Hospital Hai Phong), Cat Tuong Audiology Center, and Child Protection Fund (CPF).

\section{Data collection}

Establishments providing early intervention services

All the management representatives of the investigated facilities were interviewed about their institutions' human resources, equipment, and unit services. Lecturers of early intervention teaching (five individuals) were also interviewed.

Children with hearing loss

The sample was selected on the basis of documentation stored by the above-mentioned facilities. The inclusion criteria were children who 
were diagnosed with hearing loss from January 2013 to December 2014 and children whose records contain full information, namely age, gender, time of disease detection, degree of hearing loss, duration of intervention services, and service usage. The exclusion criteria were patients for whom records are inadequate, children who switched treatments, children older than 15 years, and children with inherited (hereditary) hearing loss. The study obtained a sample of 353 children.

\section{Parents of children with hearing impairment}

A total of 30 parents were interviewed regarding their satisfaction or dissatisfaction with the services provided by diagnostic and treatment facilities.

\section{Data analysis}

The interview data were recorded for qualitative and statistical evaluation using Microsoft Excel 2010. Fisher's exact and Chi-square tests were performed to assess relevance between ratios. $p<0.05$ was considered statistically significant.

\section{Ethical considerations}

Consent was obtained from the participating research institutions, families, and subjects (children $>12$ years old). The participants were guaranteed benefits in examination and treatment and were assured of the confidentiality of the information that they shared. They were also informed that such information will be used only for research and the achievement of public health goals.

\section{RESULTS AND DISCUSSION}

\section{Human resources of service providers}

Tables 1 and 2 show that almost all the investigated health facilities are lacking in human resources, who are also unevenly distributed. Only Cat Tuong Center is fully staffed for a closed early intervention process. The deaf school has 23 teachers and health workers, of whom 16 teachers handle a culture subject, 6 are vocational educators, and 1 is a general practitioner providing medical and hearing care. Teachers with more than 10 years of service account for the majority $(73.9 \%)$ of the employees in the school, but only 2 are trained in special education $(8.7 \%)$.

The results are similar to those derived by Phuonng [8], who surveyed some specialized schools in Ho Chi Minh City. The author found that most of the institutions do not have separate personnel who handle assignments related to early intervention services. These responsibilities are assigned to teachers, who must also undertake many tasks associated with teaching, thereby preventing them from devoting professional investment in the aforementioned services [8]. This situation was also discussed in some other studies, which identified it as a major challenge for the education sector [9-11]. This finding also underscores the need to foster expertise specific to early intervention among officials and teachers who directly participate in corresponding initiatives so that they can improve their knowledge and skills.

\section{Facilities of service providers}

Table 3 shows that apart from a private hearing center, which is a unit with sufficient facilities for services ranging from early screening to intervention, all other necessary equipment for screening and diagnosis are wanting in the evaluated public health facilities. The same conditions plague the system of public health facilities in general and that of otolaryngology in particular, as reported in other studies $[9,10,12]$.

\section{Service provision activities}

Early intervention services are lacking and inadequately distributed at the facilities. Early screening and diagnostic services for children under 3 years of age and hearing aid services are provided only by Cat Tuong Center. The BTTE Fund serves a limited function, giving humanitarian gifts to deaf students only during holidays and Tet. The early screening and diagnosis as well as support and treatment counseling at the health facilities have failed to promote the effective implementation of key roles in these activities because of the lack of workforce and equipment. These deficiencies considerably affect access to services by members of children's families, especially those hailing from remote areas and suffering from poor economic conditions (Table 4).

The in-depth interviews with the parents of the hearing-impaired children unraveled the difficulties that the families encounter when they seek services at health facilities, even at the central level, given the absence of devices for diagnosing children. These problems cause delays in diagnosis and treatment. As lamented by one of the parents:

"I found that my son had hearing loss at 20 months of age and sent him to Hai Phong Children's Hospital. My child was diagnosed with poor hearing condition, but the doctors had no machine to measure hearing. Our family also did not receive reasonable advice on the next intervention."

Another parent stated that he was compelled to travel to Ho Chi Minh City for a diagnosis and listening lessons. After a year, he returned to Hai Phong, but because of the late diagnosis, his hearing remains unclear.

In the United States, each state and territory has a system for the early detection of hearing impairment and corresponding intervention. All newborns are screened for pre-discharge hearing at a rate of $>95 \%$, then followed up if a problem occurs. They are screened for a second time for intensive auditory diagnosis. Children who have not been screened or were born at home or at midwifery centers also have easy access to services in a given locality, including those offered at private hearing centers or clinics $[5,13]$. The situation in the US indicates that enhancing the availability of services at health facilities requires regulatory agencies, health authorities, and private and social institutions to pay more attention to the provision of adequate diagnostic and treatment facilities.

\section{Coordination of management and social agencies}

Early intervention is an ongoing process that covers screening to diagnosis and intervention and includes family support, thus requiring close collaboration among different domains. This research discovered that the education, health, and social protection disciplines in Vietnam operate separately, without a clear functional relationship among them. This problem was similarly described in several other studies in the country $[8-10,14]$, thus highlighting the necessity of establishing and maintaining an interdisciplinary coordination program for the organization of service provision, the construction of a counseling system, and communication to the community regarding the benefits of early intervention for deaf children under the same regimes and policies for this population segment. The shortcomings in early intervention services have directly affected the beneficiaries of such treatments and their families.

Table 1: Human resources in early intervention facilities

\begin{tabular}{lllll}
\hline Characteristics & Viet Tiep Hospital & Children's Hospital & OG Hospital Hai Phong & Cat Tuong Center \\
\hline Ear-nose-throat doctor & 9 & 5 & - & 1 \\
Rehabilitation doctor & 5 & 5 & - & - \\
Audiologist & - & 1 & - & 3 \\
Teachers teach early intervention & - & - & - & 4 \\
\hline
\end{tabular}


Access to and use of early intervention services among hearingimpaired children

The survey results showed that family members discovered the condition of $98 \%$ of the hearing-impaired children, whereas teachers and health workers recognized the disability in only $2 \%$ of the patients. This is consistent with the findings that $62 \%$ of the children were initially diagnosed as having hearing loss and that $76.8 \%$ received a definitive diagnosis at higher level hospitals in Hai Phong (33.2\% and

Table 2: Human resources at the Hai Phong Deaf School

\begin{tabular}{ll}
\hline Characteristic & $\mathbf{n}(\mathbf{\%})$ \\
\hline Degree training & \\
University & $21(91.4)$ \\
Colleges & $1(4.3)$ \\
Intermediate & $1(4.3)$ \\
Specialized training & \\
General pedagogy & $20(87)$ \\
Special education & $2(8.7)$ \\
Medical & $1(4.3)$ \\
Experience (years) & \\
s5 & - \\
5-10 & $6(26.1)$ \\
$\geq 10$ & $17(73.9)$ \\
Professional activities & \\
Teaching culture & $16(69.6)$ \\
Vocational training & $6(26.1)$ \\
Medical & $1(4.3)$ \\
Total & $23(100.0)$ \\
\hline
\end{tabular}

$16.7 \%$ ). The time delay with respect to age of diagnosis is $>3$ months. The difference in such ages between deaf children in Central Vietnam and those living in remote areas is statistically significant. Table 5 presents results regarding the delay in the ages of initial detection and intervention in deaf children.

Fig. 1 depicts the rate of hearing aid use and early intervention implementation for the 353 hearing-impaired children. A minimal proportion of children receive speech therapy services and close attention from family members. Further analysis revealed that when newborn screening is unavailable, the responsibility of detecting

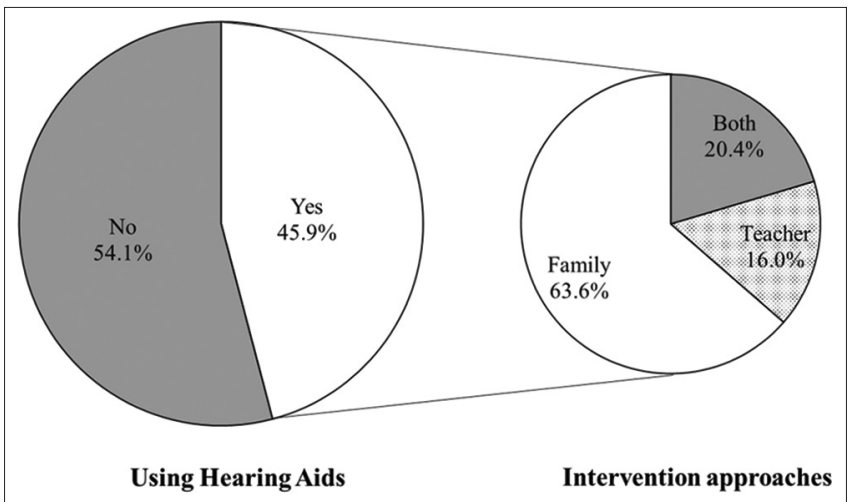

Fig. 1: The percentage of children using hearing aids and the intervention approaches

Table 3: Facilities in early intervention service providers

\begin{tabular}{|c|c|c|c|c|c|c|}
\hline Characteristics & $\begin{array}{l}\text { Viet Tiep } \\
\text { Hospital }\end{array}$ & $\begin{array}{l}\text { Children's } \\
\text { Hospital }\end{array}$ & $\begin{array}{l}\text { OG Hospital Hai } \\
\text { Phong }\end{array}$ & $\begin{array}{l}\text { Cat Tuong } \\
\text { Center }\end{array}$ & $\begin{array}{l}\text { Hai Phong Deaf } \\
\text { School }\end{array}$ & BTTE \\
\hline \multicolumn{7}{|l|}{ Special room } \\
\hline Soundproofing & 1 & 1 & - & 1 & 1 & - \\
\hline Early intervention room & - & - & - & 3 & 4 & - \\
\hline \multicolumn{7}{|l|}{ Specific equipment } \\
\hline Screening (OAE) & - & - & - & 1 & - & - \\
\hline Single tone audiometer & 1 & 1 & - & 1 & 1 & - \\
\hline Measure the eardrum and measure the pedal reflex & - & - & - & 1 & 1 & - \\
\hline Devices to calibrate hearing aids & - & - & - & 1 & - & - \\
\hline Kits for ear-nose-throat examination & 2 & 2 & - & 1 & 1 & - \\
\hline Ear-nose-throat endoscopy kit & 1 & 1 & - & - & - & - \\
\hline
\end{tabular}

Table 4: Types of early intervention services provided in 2012

\begin{tabular}{|c|c|c|c|c|c|c|}
\hline \multirow[t]{2}{*}{ Service providers } & \multicolumn{6}{|c|}{ Types of services } \\
\hline & Screening & Diagnose & Provide hearing aids & Audiological care & Counseling and family support & Speech therapy \\
\hline Viet Tiep Hospital & - & - & - & + & - & - \\
\hline OG Hospital Hai Phong & - & - & - & - & - & - \\
\hline Hai Phong Deaf School & - & - & - & + & + & + \\
\hline Cat Tuong Center & + & + & + & + & + & + \\
\hline BTTE & - & - & - & - & - & - \\
\hline
\end{tabular}

+: Available, -: Unavailable

Table 5: Age of detection, diagnosis, wear, and intervention of hearing-impaired children

\begin{tabular}{|c|c|c|c|c|c|}
\hline \multirow[t]{2}{*}{ Age (months) } & \multirow[t]{2}{*}{$\mathbf{n}$} & \multicolumn{4}{|c|}{ Mean (months) } \\
\hline & & Mean & SD & Median & Minimum-maximum \\
\hline Age discovered & 353 & 22.3 & 7.8 & 24 & $1-60$ \\
\hline Initial diagnosis age & 353 & 27.6 & 9.9 & 28 & $2-72$ \\
\hline Age of diagnosis determined & 353 & 34.0 & 12.5 & 34 & $4-72$ \\
\hline Age of wear & 162 & 33.8 & 13.3 & 34 & $8-72$ \\
\hline Age intervention & 59 & 32.5 & 12.4 & 30 & $12-72$ \\
\hline
\end{tabular}


hearing loss is assumed primarily by family members. With the limited knowledge and attention of parents, children are often diagnosed late in disease progression and miss the best stage for language development. The same issues occur among hearing-impaired children in 33 provinces/cities across Vietnam [15] and other developing countries [16-18]

\section{CONCLUSION}

The study showed inadequacies in both intervention supply and usage. Weaknesses remain in the ability of service providers to offer facilities, equipment, and personnel. Room for improvement also exists as to interdisciplinary coordination and community awareness regarding the need for early detection and intervention for deaf children. Finally, the data demonstrated the need to reinforce service delivery systems to help children with hearing impairment enjoy access to early detection and intervention

\section{ACKNOWLEDGMENTS}

The author would like to acknowledge all the staff of health facilities for data collection.

\section{DISCLOSURE}

The authors have no conflicts of interests to declare.

\section{FUNDING}

None.

\section{REFERENCES}

1. World Health Organization. Addressing the Rising Prevalence of Hearing Loss. Geneva: World Health Organization; 2018.

2. World Health Organization. Deafness Prevention: World Health Organization; 2019. Available from: https://www.who.int/deafness/ estimates/en.

3. Centers for Disease Control and Prevention. Hearing Loss in Children: Hearing loss Treatment and Intervention Services; 2019. Available from: https://www.cdc.gov/ncbddd/hearingloss/treatment.html.

4. Decker KB, Vallotton CD. Early intervention for children with hearing loss: Information parents receive about supporting children's language. J Early Interv 2016;38:151-69.

5. World Health Organization. Newborn and Infant Hearing Screening: Current Issues and Guiding Principles for action. Geneva: World Health Organization Press; 2010.

6. Yoshinaga-Itano C, Sedey AL, Coulter DK, Mehl AL. Language of early and later-identified children with hearing loss. Pediatrics 1998;102:1161-71

7. Yen NT. Special Education and Basic Terms [in Vietnamese]. Hanoi, Vietnam: University of Education Publishing House; 2012.

8. Phuonng DT. Current Situation of Early Intervention for Deaf Children in Some Specialized Schools in Ho Chi Minh City. Ho Chi Minh City: Pedagogical University Scientific Topics at the Grassroots Level; 2010.

9. Ministry of Education and Training. Policies, Strategies and Plans for Inclusive Education Development in Vietnam. Hanoi, Vietnam: Ministry of Education and Training; 2011.

10. Huu ND. Current situation and orientation for the development of education for children with disabilities in Vietnam in the period 20152020 [in Vietnamese]. J Edu 2014;8:2-6.

11. Le NV. Research Report on Human Resource Capacity for Early Intervention of Vietnamese Children with Disabilities. Hanoi, Vietnam: Ministry of Health; 2012.

12. Yen NT. General Education about Hearing-impaired Children [in Vietnamese]. Hanoi, Vietnam: University of Education Publishing House; 2007.

13. White KR. The current status of EHDI programs in the United States. Ment Retard Dev Disabil Res Rev 2003;9:79-88.

14. UNICEF and the Ministry of Labour, War Invalids, and Social Affairs. Qualitative Research on Children with Disabilities in An Giang and Dong Nai: Knowledge Attitude Practice [in Vietnamese]. Hanoi, Vietnam: Ministry of Labour, War Invalids, and Social Affairs; 2011.

15. Thiep TT. Some Measures to Implement Early Intervention for Deaf Children [Vietnamese]. Hanoi, Vietnam: Hanoi National University of Education; 2004

16. Jafari $\mathrm{Z}$, Malayeri S, Ashayeri $\mathrm{H}$. The ages of suspicion, diagnosis, amplification, and intervention in deaf children. Int $\mathrm{J}$ Pediatr Otorhinolaryngol 2007; 71:35-40

17. Ozcebe E, Sevinc S, Belgin E. The ages of suspicion, identification, amplification and intervention in children with hearing loss. Int $\mathrm{J}$ Pediatr Otorhinolaryngol 2005;69:1081-7.

18. Robertson C, Aldridge S, Jarman F, Saunders K, Poulakis Z, Oberklaid F, et al. Late diagnosis of congenital sensorineural hearing impairment: Why are detection methods failing? Arch Dis Child 1995;72:11-5. 